Canadian Oncology

Nursing Journal

Revue canadienne

de soins infirmiers

en oncologie

Volume 30, Issue 4 • Fall 2020

elSSN: 2368-8076 


\title{
Nurses' experience with palliative sedation procedures in line with the 2005 Swiss guidelines: an exploratory study
}

\author{
by Martyna Tomczyk and Bernard N. Schumacher
}

\begin{abstract}
Many international studies have shown that the process of palliative sedation in an end-of-life context can be an adverse, even emotionally distressing experience for nurses. However, to the best of our knowledge, the experience of nurses working in palliative care in Switzerland has never been explored. The purpose of our study was, therefore, to understand and describe nurses' experience with the process of palliative sedation in line with the Swiss guidelines developed in 2005. We opted for an exploratory qualitative monocentric study using comprehensive individual interviews to achieve this objective. A total of 10 nurses were approached, and nine agreed to take part. After the interviews were transcribed, eight were ultimately included in the analysis. This analysis shows that nurses' attitudes toward the process of palliative sedation tended to be hesitant, resistant, or confident and that this was linked to the length of time they had worked in palliative care. These findings suggest that the 2005 Swiss guidelines do not protect nurses against the uncertainty related to process of palliative sedation. A national comprehensive multicentric study therefore needs to be developed to consolidate these results.
\end{abstract}

Keywords: palliative sedation, palliative care, end of life, nurses, experience, qualitative study.

\section{INTRODUCTION}

Sedation in the broad sense of the term is an important practice and one that is critical in the field of palliative care (Cherny \& ESMO Guidelines Working Group, 2014; Cherny, et al., 2009). However, from an epistemological point of view, there is no unique and universally accepted definition of this concept. A number of terms and expressions are used, and they are not all conceptualized in the same way, be it in the worldwide medical literature (Papavasiliou, Payne, et al.,

\section{AUTHOR NOTE}

Martyna Tomczyk (Contact Author)

Medical Ethics Researcher, PhD, Postdoctoral Fellow, Institute of Humanities in Medicine, Lausanne University Hospital (CHUV), Avenue de Provence 82,

CH-1007 Lausanne, Switzerland

martyna.tomczyk5891@gmail.com

+33(0)695118645

Bernard N. Schumacher, Philosopher, Professor, PhD-HDR, Coordinator, Interdisciplinary Institute of Ethics and Human Rights, University of Fribourg, Switzerland.

Avenue de Beauregard 13, CH-1700 Fribourg, Switzerland

bernard.schumacher@unifr.ch

DOI:10.5737/23688076304261268
2013; Papavasiliou, Brearley, et al., 2013) or in the recommendations for best practices issued at the national or European level (Abarshi et al., 2017; Gurschick et al., 2015; Schildmann \& Schildmann, 2014).

In Switzerland, a group of experts from the Swiss Association for Palliative Medicine, Care and Support published a set of formal guidelines for palliative sedation in 2005. In it, these experts chose to use the term "sédation palliative" (palliative sedation), defining it as the intentional administration of sedative substances at the minimum dosage required to relieve one or more refractory symptoms by a temporary or permanent reduction in consciousness of a patient with an advanced illness who is not expected to live beyond a matter of days or weeks and to do so in cooperation with a skilled, multidisciplinary team (Groupe d'experts de la Société suisse de médecine et de soins palliatifs, 2005, p. 1). These guidelines have since served as a framework for palliative sedation in Switzerland. A range of protocols and tools have been developed locally, in Swiss institutions providing palliative care, to allow these guidelines to be implemented. For example, the palliative care unit team at the Fribourg hospital (HFR) in Villars-sur-Glâne in the canton of Fribourg in French-speaking Switzerland developed a tool to monitor patients and meet the needs of the team in charge of the palliative sedation process in compliance with the 2005 Swiss guidelines (Francisco \& Cantin, 2013).

Although there are a few other studies on palliative sedation in Switzerland, they are essentially written from the perspective of doctors (Beauverd et al., 2014; Dumont et al., 2015; Foley et al., 2015; Ziegler et al., 2018). To date, we have found only one study in the databases we examined that addresses the issue from a nursing point of view (Tomczyk \& DieudonnéRahm, 2019).

The Swiss guidelines (2005), like other guidelines (Cherny \& ESMO Guidelines Working Group, 2014; Cherny et al., 2009; Società Italiana di Cure Palliative, 2007; Société québécoise des médecins de soins palliatifs \& Collège des médecins du Québec, 2016; Royal Dutch Medical Association, 2009) do not specifically define the role of nurses in palliative sedation. Yet, it seems to us that this role is essential at every point in the process. For example, during the initial phase, nurses can take part in team discussions, without making any decisions as these fall within the scope of physicians. Moreover, their role is critical in administering sedation, monitoring patients, and assessing their comfort. However, this type of involvement may be difficult for nurses to deal with and may even 
lead to a state of emotional distress, as has been shown in a number of studies (Abarshi et al., 2014; Lokker et al., 2018; Zuleta-Benjumea et al., 2018). Up until now, ${ }^{1}$ to the best of our knowledge, the experience of nurses working in a palliative sedation context in French-speaking Switzerland has not been explored.

The purpose of our study was therefore to understand and describe the experience of nurses in a palliative care unit providing palliative sedation based on the 2005 Swiss guidelines. By "experience," we mean "something personally encountered, undergone, or lived through" ("Experience," n.d.), bearing in mind that any such experience is inevitably subjective in nature.

\section{MATERIALS AND METHODS}

The information about the experience of nurses in this regard was derived from interviews conducted during a previously published study on the conceptualization of palliative sedation (Tomczyk \& Dieudonné-Rahm, 2019). This information spontaneously emerged from these findings and were the most dominant among them. This is a secondary analysis of these data (Brugidou et al., 2005). Consequently, with the exception of the subparagraph related to data analysis, the other subparagraphs below automatically refer to this conceptualization study (Tomczyk \& Dieudonné-Rahm, 2019).

This was an exploratory qualitative study based on comprehensive interviews (Blanchet \& Gotman, 2010). It was conducted in accordance with the Consolidated Criteria for Reporting Qualitative Research - COREQ (Tong et al., 2007) over a three-week period, between October and November 2017.

\section{a) Legislative and ethical considerations}

In accordance with applicable Swiss legislation, this non-interventional study, which does not include the collection of any personal health data and does not directly concern patients, did not need to be reviewed by an ethics committee. The authorization of the head of the department where the study was being conducted was nevertheless secured, and the verbal consent of each participant was systematically sought out and obtained. Furthermore, participants all gave their consent for the interviews to be recorded using a sound recording device. In order for the department head and participants to be able to give their free and informed consent, the following information was presented to them: the study objectives, the nature of the information being gathered, the style of interview (a comprehensive interview with a secondary data analysis), the expected type of participation (type of questions and approximate length of the interview) and the reason for the request to take part in the interview. Participants were reminded of their rights, such as the right to refuse to take part in the study, the right to decline to answer questions and the right to terminate the interview without providing an explanation. It was also pointed out that no information that would make it possible

1 November 2017, March 2020. to personally identify the participants would be included in any publications resulting from this study. Lastly, interviewees were advised that this study was being conducted as part of Martyna Tomczyk's postdoctoral research.

\section{b) Study location}

The palliative care station at the Fribourg hospital (HFR), located in Villars-sur-Glâne in the canton of Fribourg in French-speaking Switzerland ${ }^{2}$ was chosen as the study site for practical reasons. At the time the study was being carried out, the station was designated as a "qualité palliative" facility by the Swiss Association for Quality in Palliative Care. ${ }^{3}$ It had 14 specialized beds and a day centre.

\section{c) Inclusion criteria}

There was only one inclusion criterion: being a nurse who agreed to take part in and who was available for the study. No restrictive criteria were imposed on participant selection.

\section{d) Inclusion methodology}

From the team of nurses working within the department, 10 professionals were chosen at random by their manager and asked to take part in an individual interview approximately 20 minutes in length. An inclusive approach spaced out over time was favoured.

\section{e) Preparation of interviews}

As these were comprehensive interviews (Blanchet \& Gotman, 2010), an interview guide was not developed beforehand to "get informants to speak indirectly about the subject in order to ideally establish a conversational dynamic" (Kaufmann, 2011). As a result, participants were each asked a single question: "What does the expression 'palliative sedation' mean to you?" Information concerning participants' experience spontaneously emerged during the course of each interview. As needed, additional questions were asked, based on the interviewees' remarks, in an effort to ensure the data obtained were reliable.

\section{f) Interviews}

The comprehensive individual interviews were all conducted by the same person, namely Martyna Tomczyk, a postdoctoral fellow in medical ethics, who had eight years of experience in qualitative research at the time these interviews were carried out. She had no reporting, family or other relationship with the head of the department or any of the participants. It was the first time any of them had met.

All interviews were held in a private setting in an available room within the department (conference room, family room, etc.). The language used in the interviews was French, which was the common language for all participants, including the interviewer (first or second mother tongue or a learned

2 The anonymity of the study location was waived by the department head.

3 Swiss Association for Quality in Palliative Care: https:// www.qualitepalliative.ch/association/? $\mathrm{L}=2$ (accessed on March 30, 2020). 
language, given that the canton of Fribourg is a bilingual canton $\left.^{4}\right)$. All interviews were recorded using a sound recording device, with the consent of each participant.

\section{g) Preparation of interviews for analysis}

All interviews were transcribed manually and in a semi-verbatim format: repetitions were omitted to prevent the data and the corresponding analysis from becoming cumbersome. Any information that could potentially be used to personally identify participants was deleted. Only the length of time the subject had worked in palliative care was retained. The transcribed interviews were not sent to participants to review or edit. All sound recordings were erased once the interviews were transcribed.

\section{h) Analysis of interviews}

The process was one of thematic analysis and continuous thematization: themes related to the nurses' experience were identified and noted as each transcription was read. They were then categorized by central themes and subthemes, with which significant excerpts were associated. Finally, the interviews were analyzed transversally, based on previously identified themes and subthemes to identify points of convergence and divergence. The entire analysis was performed manually by Martyna Tomczyk. Out of a concern for scientific rigour and in an effort to reduce subjectivity bias, the interviews were analyzed twice more by the same person with a certain amount of time between each analysis. Adjustments from the second and third analysis were incorporated. The results following the third analysis were reviewed by Bernard Schumacher.

\section{RESULTS}

Ten nurses ${ }^{5}$ were approached to participate in the study. Nine of these ten were available and did indeed take part. The saturation point was reached around the fourth interview; the subsequent interviews did not contribute any new elements, and each interview became more and more redundant (Alami et al., 2009; Mucchieli, 2004; Van Campenhoudt $\&$ Quivy, 2011). The study nevertheless continued up until the ninth interview in order to ensure the process was carried out with all due caution and diligence. Accordingly, nine interviews were conducted and submitted for transcription. During the transcription process, however, one interview had to be rejected due to the substandard quality of the sound recording. A total of eight interviews were, therefore, included in the analysis.

The anticipated length of the interview was about 20 minutes, although it proved to vary from one interview to the next: the shortest lasted 12 minutes and the longest 52 minutes. The total combined length of the interviews was three hours and 14 minutes.

The experience of the nurses interviewed was structured around three key and independent attitudes: hesitant, resistant, and confident.

\footnotetext{
4 French and German.

5 In order to protect participants' anonymity, their personal details have not been included in this paper.
}

\section{Hesitant}

Most of the nurses interviewed (6/8) expressed hesitancy about the process of palliative sedation and were unsure about the fundamental issue of patient comfort.

\section{a) Is the patient genuinely comfortable? Does the sedation fully relieve their suffering?}

The uncertainty as to the patient's comfort under palliative sedation was the main concern reported by the majority of nurses (6/8), as the following comment indicates:

"The patient is put into a coma and after that... we wonder what the experience is like for them... That's the main concern. From my point of view, it looks like they're sleeping. They're calm. But I don't know what's actually going on inside their head. [...] We don't know what they're feeling. That's my biggest worry. [...] There are some kinds of sedation... not many, but a few... For them, it was intolerable... They didn't react very well at all. There were stories of nightmares. The person was very happy to have been taken off sedation so they weren't trapped inside the nightmares anymore. Since then, I've had more and more questions" (IDE No. 1).

One nurse $(1 / 6)$ became more aware of this uncertainty during the actual interview:

"Being sedated is another way of living. You know... Now, I'm thinking more about it... For example, when I'm on a night shift, I do regular rounds and I see patients who are sleeping soundly. Actually, I only think I see them sleeping soundly. In the morning, some of them tell me they've had a bad night. So, clearly, there's something unknown between what we can see and what patients experience while they're asleep... (whether that sleep is natural or artificial). So, after that, the question has to be asked: is sedative-induced sleep any different from normal sleep? Basically, what I'd like to say is that we can never be totally sure about what is going on inside the head of a patient under sedation."

(IDE No. 2)

\section{b) Elements that further qualify the nurses' hesitant attitudes}

Two main elements that help qualify nurses' hesitant attitudes were identified, namely an in-depth assessment of a patient's situation by the healthcare team and the possibility and management of the assessment by the patient after they are taken off sedation.

- Assessment of the sedated patient's comfort by the healthcare team (6/6):

"When I do a sedation assessment, I always look at the patient's face. There's a certain amount of guesswork to be done. When someone is sedated... There are clinical signs that we can't observe, but the face... the face is a special thing... It's very unique. If they are suffering in any way, you can see it right away on their face, even if they're asleep. I don't know how to explain it... It's really quite mysterious... But it's always right there on their face. [...] For example, a patient might wince or screw up their face... That's a sign for us that they are in pain." (IDE No. 2) 
- Self-assessment of a patient's comfort, after they are taken off sedation $(6 / 6)$ :

Personally, I am very relieved when a patient is taken off sedatives and can tell us how they were feeling. [...] Once they aren't sedated anymore, we ask the patient how they feel, how their experience being sedated was. That is very important for me. We can get their feedback. We can talk about it. For some of our patients who were in a great deal of pain and wanted to be sedated, once they were taken off the sedatives, they didn't want to go back on them. They didn't like the way the sedatives made them feel. They felt disconnected from their family. So, for them, this was a very important conversation to have. I think it's very important for them to be able to describe their experience." (IDE No. 4)

To sum up, the main source of the hesitant attitude toward sedation was patient comfort. The comfort assessment, whether it is performed by the healthcare team when the patient is sedated or by the patient once they are taken off sedation, tended to mitigate this hesitancy. The comfort self-assessment was even more reassuring in that it helped eliminate the subjective component of a nurse-administered assessment.

\section{Resistance}

One nurse $(1 / 8)$, who had worked the longest in palliative care, was resistant toward the process of palliative sedation.

a) Is it appropriate to administer palliative sedation knowing that it does not relieve a patient's suffering?

This nurse $(1 / 8)$ was certain that patients' suffering was not relieved by palliative sedation, identifying this as their primary concern. The explanation offered was as follows:

"Just because someone isn't moving or reacting, it doesn't mean they aren't in pain. I mean, there are patients who are taken off sedation and tell us they weren't comfortable... It makes you think... That's enough for me! All the papers doctors publish are fine and dandy. But I'd rather hear what patients have to say instead of read doctors' research. [...] Personally, I don't think it eases anyone's suffering. I think that suffering and sedation... The way I see it... I can never promise anyone they won't be in pain when they're under sedation... Never! [...] I think that suffering is part of the human condition, and we can't solve everything with a drug prescribed by a doctor." (IDE No. 8)

To elaborate further, this nurse made reference to a clinical situation:

"I still remember a situation (it wasn't here). The patient was confused and in agony. I think he was reliving things from his past. The doctor wanted to have him sedated. I said, 'No!' I stayed with him. He calmed down and started telling me all sorts of things. We talked and talked, and he finally fell asleep. He had a good night. Two days later, when I was back to work, he had been pumped full of sedatives. He died three days later... So that's that. I think sedation is a way of avoiding things. Avoiding having to deal with a patient's suffering. We just shut it down. And that's what makes me uncomfortable with the whole thing." (IDE No. 8)
The same nurse implied that palliative sedation may even make a patient's suffering worse:

"It's important to remember that sedation can be worse than the suffering itself. I remember one patient who was sedated. When she was weaned off... She told me she felt absolutely awful while she was under and didn't want to stay sedated. So I'm skeptical about it... I always tell doctors, 'Careful, don't play God.' We have tools. But I think we have to be honest and say, 'We don't know everything, and we can't make all suffering go away!'” (IDE No. 8)

\section{b) Elements that further qualify the nurse's resistant attitude}

Given this resistance, the nurse preferred maintaining a personal presence over the use of palliative sedation:

“When you're with a patient who's terminally ill, they open up... They start to explain what's wrong. [...] If we can't do anything for them on the technical side, the best thing is to simply stay with them. Sometimes, just being there is enough to soothe their pain. I've seen this happen over and over again... but being there for them takes a lot of time..." (IDE No. 8)

\section{Confidence}

One nurse $(1 / 8)$, the one who had spent the least time working in palliative care, expressed confidence about the process of palliative sedation.

\section{a) A confident attitude toward palliative sedation}

The nurse reported a positive experience with regard to the use of palliative sedation and stated it was consistent with their own patient care values. Unlike the other nurses we interviewed $(7 / 8)$, this nurse did not explicitly address the issue of relieving a patient's suffering. Here's what they had to say:

"I don't feel like we're doing them any harm... the times I've experienced sedation have been a real relief. In my view, it's very much done with respect to the patient." (IDE No. 6)

\section{b) Main elements contributing to the confidence in the use of sedation}

Two elements were crucial in creating a positive sedation experience for this nurse:

- Assessment of the patient's comfort during sedation by the healthcare team:

"What's more, the assessment is done by us [...] It always has to be done using our chart." (IDE No. 6)

- Self-assessment of the patient's comfort after they have been taken off sedation:

“There's something that helps me personally, and that's when the patient is taken off sedation. After 24 hours, we stop administering the sedatives and we try to see the patient. [...] We always use this chart, which is a great source of support for us. [...] Taking them off sedation lets us see if the sedatives have been working. We talk to the patient. Sometimes, this first experience reduces their anxiety and we don't have to put them back on sedation. In those cases, it's a positive thing." (IDE No. 6) 
To sum up, most nurses were somewhat hesitant $(6 / 8)$, even resistant $(1 / 8)$, with regard to the process of palliative sedation. Both attitudes were largely attributable to the uncertainty surrounding patient comfort. There seem to be slightly varying levels of hesitancy, whereas resistance appears to be unalterable.

On the other end of the continuum, one nurse had a fairly confident attitude toward the process and there seemed to be room for this confidence to grow even stronger.

The above results have been summarized in Figure 1.

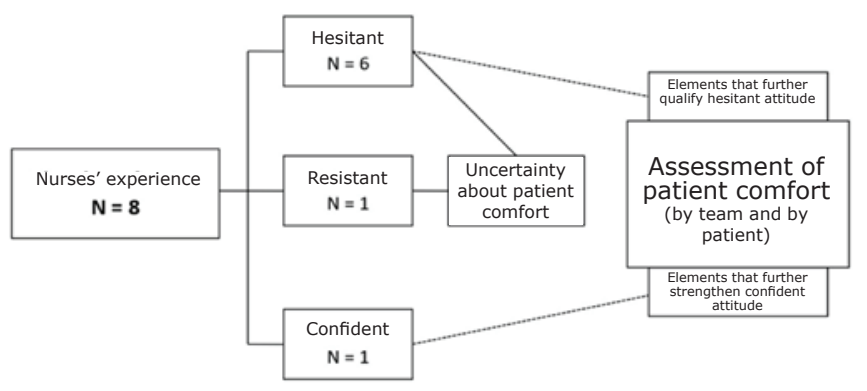

Figure 1: Figure 1: Recap of findings

\section{DISCUSSION}

Our exploratory qualitative study, focused on the experience of nurses with palliative sedation administered in accordance with national guidelines in French-speaking Switzerland, is unlike any other study carried out to date. It essentially highlighted three categories of nurses' experience in this regard, one of which-hesitancy-dominated the others. In addition, it emphasized a link between experience and the length of time spent working in palliative care: more experienced nurses tended to be more hesitant, even resistant, in their attitude toward sedation, whereas the nurse who had spent less time working in palliative care was more confident in the process. The assessment of patient comfort by the healthcare team and the self-assessment by the patient was reassuring for all participants, except for the one resistant nurse.

More specifically, most of the nurses interviewed were hesitant in their attitude toward palliative sedation, with one who was resistant. This was due to the uncertainty as to the relief that this method actually provided for patients' suffering. Although the goal of palliative sedation is to alleviate one or more refractory symptoms by reducing the level of consciousness (Groupe d'experts de la Société suisse de médecine et de soins palliatifs, 2005), it should be noted that it is not meant as a treatment designed to suppress the symptom(s) through pharmacological means acting on psychopathological mechanisms, but rather a treatment to reduce or eliminate the perception of the symptom(s) by altering awareness (Davis, 2009a). Although healthcare professionals have access to clinical observational scales such as the Critical Care Pain Observational Tool, the Behavioral Pain Scale and the Échelle comportementale de la douleur chez la personne âgée durant les soins, these tools have certain limits. These scales have been developed in other contexts and in most cases have not been validated in this specific situation. They are also, by definition, reliant on observation and therefore highly subjective and open to interpretation (Brinkkemper et al., 2013; Pudas-Tähkä et al., 2009). It has been demonstrated that assessments done by doctors differ from those performed by nurses and that non-clinical factors such as the religion and age of the caregiver can influence these results (Demertzi et al., 2009).

In addition, although there are scales to assess pain and dyspnea, as subjective as they may be, tools that would make it possible to evaluate other physical symptoms (e.g., nausea) and, even more important, mental, existential, and emotional suffering $^{6}$ are lacking. However, reduced awareness brought on by sedation does not stop the brain from functioning, which is what potentially leads to anxiety, nightmares, and an altered perception of the environment. Scientific research on the topic is not abundant in the palliative care field (Davis, 2009b; Kon, 2011), but there are some studies on record in anesthesia and reanimation (Ghoneim, 2007; Ghoneim et al., 2009; Leslie et al., 2010; Sanders et al., 2012). It is interesting to note that, despite these limitations, the assessment was cited by the nurses interviewed as part of the study as a source of reassurance in the palliative sedation process.

It should also be pointed out that the interviewees attached great importance to a patient's face when assessing their comfort, all while acknowledging that such a practice is difficult to defend scientifically. In an effort to enrich the discussion from an interdisciplinary perspective, we have turned to the field of philosophy to put forward a few elements to be considered. For example, Emmanuel Levinas emphasizes that the face is "not the mere assemblage of a nose, a forehead, eyes, etc." (Levinas, 1995, p. 20), but takes on a new dimension that transcends the idea we may have of the Other. The face "is not 'seen." It is "what cannot become a content" (Levinas, 2009, p. 81), which inevitably leads to something beyond the realm of factual knowledge. The face shows more than this and yet defies any attempt to define what that might be. The Other, as Levinas put it, "takes on the meaning of a face through the new dimension it opens up in the perception of a being. Through the face, the being is not only enclosed in its form and offered to the hand, it is also open, establishing itself in depth and, in this opening, presenting itself somehow in a personal way." (Levinas, 2009, p. 20). This relationship with the Other can be expressed in a very unique way when a person is experiencing the isolation of suffering and death: "Only a being whose solitude has reached a crispation through suffering, and in relation with death, takes its place on a ground where the relationship with the Other becomes possible." (Levinas, 1983, p. 64). The face never stops communicating, reaching out for a response from the caregiver, a response that falls within the

6 The potential differences among these three concepts go beyond the scope of this paper and have, therefore, not been expanded upon here. 
unconditional responsibility toward the Other: "answering the Other, which leads to vouching for them" (Levinas, 2009, p. 83; Pierron et al., 2019).

Thus far, a patient's self-assessment remains a reliable method. Although it is impossible to use it in cases of deep and continuous sedation leading up to death, it is possible in cases of temporary sedation. Once the sedation has been discontinued, the patient can describe their experience. This approach, which is perfectly in line with the 2005 Swiss guidelines, was indeed a source of reassurance for all the nurses interviewed except one. It is noteworthy, however, that although deep and continuous sedation leading up to death was not specifically cited as a main purpose of the Swiss experts in this national document, it is a different story elsewhere in Europe. In fact, European experts actually recommend this type of sedation in certain well-defined situations (Cherny et al., 2009).

Last but not least, it is important to discuss the experience of the nurse who, unlike the others, showed a resistant attitude toward the process of palliative sedation. This nurse considers it to be an inefficient practice in treating a patient's suffering, to the point of potentially making matters worse, and deemed it a hindrance to establishing a true caregiver-patient relationship, which they considered to be the only true way of easing suffering. First and foremost, it is important to emphasize that the "relationship between human beings," as Levinas puts it, "has an essentially non-synthesizable character." (Levinas, 2009, p. 71). However, it is certain that "true union or togetherness is not a togetherness of synthesis, but togetherness of face-to-face." (Levinas, 2009, p. 72). Yet, the relationship between the healthcare professional whose "power to act is, initially, greater than the Other's power to act" (Ricoeur 1990, p. 255) and the Other who is suffering - vulnerable and fragile - is by its very nature an asymmetrical relationship, hence the need to incorporate a certain reciprocity. Paul Ricoeur specifies that "reciprocity [...] breaks away from the background of the presupposition of an initial dissymmetry between the protagonists of the action - a dissymmetry that puts one in the position of agent and the other in the position of patient" (Ricoeur, 1990, p. 255). If humans are "beings of reciprocity" (Malherbe, 1997, p. 26), this fundamental reciprocity manifests itself as "the shared responsibility of all human beings to keep their word to each other" (Malherbe, 1997, p. 29). For this philosopher, keeping one's word is "the goal, the destination and the means of reciprocity" (Malherbe, 1997, p. 26), which is consistent with what the interviewed nurse said during our study. The nurse emphasized that a relationship based on this is apt to soothe a patient's suffering. These remarks seemed even more interesting in that suffering is a universal, even existential, experience, linked to a pain felt within the body or perhaps independent of it (Perrot, 2016). A few decades ago, Cicely Saunders (1993), a pioneer in the palliative care movement, noted that presence and attentive listening in a caring environment can help soothe physical pain. Conversely, an analgesic can be inefficacious if suffering (mental anguish) is not addressed. In this regard, Verspieren (1984) asserts that the best cure for suffering is "a simple, genuine and deep relationship with the person who is sick" (p. 111). If such a relationship is indeed likely to be a form of care in and of itself, it is, to quote Aubry, "a very difficult type of care because there is no knowledge, strictly speaking, about what is causing the suffering" (Aubry, 2011, p. 230).

Before concluding, it is worth taking a closer look at the four main methodological limitations of our study. First, it seems important to ponder whether retrieving information about past experience from the data from a study whose main goal was to discover and describe the conceptualization of palliative sedation by nurses is methodologically acceptable. The study did not openly address the question of experience. To answer this, we need to restate that the objective of the research on the exploratory conceptualization based on comprehensive interviews was not to explain a specific phenomenon but rather to engage us in the field to shed light on various facets of a highly complex reality (Alami et al., 2009; Paillé \& Mucchielli, 2012). Nurses' experience was the dominant aspect. Additionally, the absence of an interview guide is something that can legitimately be called into question. We chose not to develop one so that the interview remained as open-ended as possible and allowed as many categories as possible to emerge. This approach is entirely consistent with the principles of qualitative research, comprehensive interviews in particular (Kaufmann, 2011). Lastly, the number of participants is likely to be criticized, although it does in fact comply with the principle of an exploratory quantitative study. In this type of research, population representativeness is not as important as the population's "social significance" (Alami et al., 2009). More specifically, the purpose of our study was not to know how many nurses have a given type of experience in the process of palliative sedation, but rather to bring out "transversal" categories to explore the study population via the individuality of each participant.

It is also important to specify that the transcribed interviews were not sent to participants to review or edit. They were submitted directly for analysis. This approach was consistent with the objective of our main study (Tomczyk \& Dieudonné-Rahm, 2019), which involved gathering conceptualizations from each nurse at a given moment, i.e., during the interview, by mental association in connection with their acquired experience at that point. The objective was not to verify theoretical or practical knowledge about palliative sedation or to assess practices within the department. Accordingly, editing participants' interviews would be contrary to the objective of the study and would in all likelihood bias the data and, by extension, the findings. Considering that this is an experience-based study, it would have been preferable for the transcribed interviews to be sent to participants (Ribau, Lasry, Bouchard et al., 2005). However, given that our study on nurses' experience resulted from a secondary analysis of the data, it was impossible for us at that stage to contact participants, due to the anonymity of the interviews, which may potentially constitute a methodological limitation.

\section{CONCLUSION}

This study made it possible to understand the experience of nurses with regard to the use of palliative sedation in line with the 2005 Swiss recommendations and a protocol put in place 
to facilitate implementation. It shed light on categories to be consolidated and further developed in other studies. Beyond the nurses' experience, it would be essential to explore the experience of patients who have received temporary palliative sedation. The data from these future studies could be useful in updating the guidelines on palliative sedation and institutional protocols, for the sake of ensuring the best possible end-of-life care for patients and preventing the risk of emotional distress among nurses.

\section{REFERENCES}

Abarshi, E. A., Papavasiliou, E. S., Preston, N., Brown, J., \& Payne, S. (2014). The complexity of nurses' attitudes and practice of sedation at the end of life: a systematic literature review. Journal of Pain and Symptom Management, 47(5), 915-25.e11. https://doi. org/10.1016/j.jpainsymman.2013.06.011.

Abarshi, E., Rietjens, J., Robijn, L. et al. (2017). International variations in clinical practice guidelines for palliative sedation: A systematic review. BMJ Supportive \& Palliative Care, 7(3), 223-9. https://doi. org/10.1136/bmjspcare-2016-001159.

Alami, S., Desjeux, D., \& Garabuau-Moussaoui, I. (2009). Les méthodes qualitatives. PUF.

Aubry, R. (2011). Réflexions sur les pratiques et le quotidien des médecins, sur le soin palliatif et le rapport à la mort dans une maladie incurable et douloureuse. Dans : Ferry, J.M, directeur, Fin(s) de vie : le débat. PUF, p. 217-241.

Beauverd, M., Bernard, M., Currat, T. et al. (2014). French Swiss physicians' attitude toward palliative sedation: Influence of prognosis and type of suffering. Palliative \& Supportive Care, 12(5), 345-50. https://doi.org/10.1017/S1478951513000278.

Blanchet, A., \& Gotman, A. (2010). L'enquête et ses méthodes : l'entretien. Armand Colin.

Brinkkemper, T., van Norel, A. M., Szadek, K. M. et al. (2013). The use of observational scales to monitor symptom control and depth of sedation in patients requiring palliative sedation: A systematic review. Palliative Medicine, 27(1), 54-67. https://doi. org/10.1177/0269216311425421.

Brugidou, M., Le Roux, D., \& Salomon, A. C. (2005). Colloque « L'analyse secondaire en recherche qualitative », Grenoble. https:// reanalyse.hypotheses.org/files/2014/09/Pr\%C3\%A9sentation.pdf (Accès le 04 avril 2020).

Centre National de Ressources Textuelles et Lexicales. Consulté sur : http://www.cnrtl.fr/definition/conceptualisation/substantif. (Accès le 04 avril 2020).

Cherny, N. I., Radbruch, L., \& The Board of the European Association for Palliative Care. (2009). European Association for Palliative Care (EAPC) recommended framework for the use of sedation in palliative care. Palliative Medicine, 23(7), 581-93. https://doi. org/10.1177/0269216309107024.

Cherny, N. I., \& ESMO Guidelines Working Group. (2014). ESMO Clinical Practice Guidelines for the management of refractory symptoms at the end of life and the use of palliative sedation. Annals of Oncology, (Suppl. 3), iii143-52. https://doi.org/10.1093/ annonc/mdu238.

Davis, M. (2009a). Palliative sedation: Four questions. Progress in Palliative Care, 17, 203-4.

Davis, M. (2009b). Does palliative sedation always relieve symptoms? Journal of Palliative Medicine, 12(10), 875-7. https://doi.org/10.1089/ jpm.2009.0148.

\section{CONFLICTS OF INTEREST}

The authors declare no conflict of interest or competing interests in relation to this paper.

\section{ACKNOWLEDGEMENTS}

Our heartfelt thanks to Dr. Boris Cantin, head of the palliative care unit at Villa St. François in the Fribourg Hospital (HFR), and Sylvie Francisco, the nurse in charge, for making this study possible. The authors would also like to express their gratitude to the nurses who agreed to take part in the study.

Demertzi, A., Schnakers, C., Ledoux, D. et al. (2009). Different beliefs about pain perception in the vegetative and minimally conscious states: A European survey of medical and paramedical professionals. Progress in Brain Research, 177, 329-38. https://doi. org/10.1016/S0079-6123(09)17722-1.

Dumont, S., Blondeau, D., Turcotte, V. et al. (2015). The use of palliative sedation: A comparison of attitudes of French-speaking physicians from Quebec and Switzerland. Palliative \& Supportive Care, 13(4), 839-47. https://doi.org/10.1017/S1478951514000364.

Experience. (n.d.). In Merriam-Webster.com dictionary. Retrieved from https://www.merriam-webster.com/dictionary/experience

Francisco, S., \& Cantin, B. (2013). Suivi de la personne recevant une sédation palliative : quelles responsabilités pour l'infirmière? Revue de la Société suisse de médecine et de soins palliatifs "palliative ch », $4:$ 47-50. https://www.palliative.ch/fileadmin/user_upload/ palliative/magazin/2013_4.pdf

Foley, R. A., Johnson, W. S., Bernard, M. et al. (2015). Attitudes regarding palliative sedation and death hastening among Swiss physicians: A contextually sensitive approach. Death Studies, 39(8), 473-82. https://doi.org/10.1080/07481187.2015.1029142.

Ghoneim, M. M. (2007). Incidence of and risk factors for awareness during anaesthesia. Best Practice Q Research Clinical Anaesthesiology, 21(3), 327-43. https://doi.org/10.1016/j.bpa.2007.05.002.

Ghoneim, M. M., Block, R. I., Haffarnan, M., \& Mathews, M. J. (2009). Awareness during anesthesia: Risk factors, causes and sequelae. A review of reported cases in the literature. Anesthesia Q Analgesia 108(2), 527-35. https://doi.org/10.1213/ane.0b013e318193c634.

Groupe d'experts de la Société suisse de médecine et de soins palliatifs. (2005). Recommandations «Sédation palliative». Consensus sur la meilleure pratique en soins palliatifs en Suisse. Bigorio. https:// www.palliative.ch/fileadmin/user_upload/palliative/fachwelt/E_ Standards/E_12_4_bigorio_2005_Sedation_fr._pdf.pdf

Gurschick, L., Mayer, D. K., \& Hanson, L. C. (2015). Palliative sedation: an analysis of international guidelines and position statements. American journal of hospice \& palliative care, 32(6), 660-71. https:// doi.org/10.1177/1049909114533002.

Kaufmann, J. C. (2011). L'enquête et ses méthodes. L'entretien compréhensif. Armand Colin.

Kon, A. (2011). Palliative sedation: It's not a panacea. American Journal of Bioethics, 11(6), 41-2. https://doi.org/10.1080/15265161.2011.5775 13.

Leslie, K., Chan, M. T., Myles, P. S., Forbes, A., \& McCulloch, T. J. (2010). Posttraumatic stress disorder in aware patients from the B-Aware trial. Anesthesia Q Analgesia, 110(3), 823-8. https://doi. org/10.1213/ANE.0b013e3181b8b6ca.

Levinas, E. (1983). Le temps et l'autre. PUF.

Levinas, E. (1995). Difficile liberté. Le Livre de Poche.

Levinas, E. (2009). Éthique et infini. Le Livre de Poche. 
Lokker, M. E., Swart, S. J., Rietjens, J. A. C., van Zuylen, L., Perez, R. S. G. M., van der Heide, A. (2018). Palliative sedation and moral distress: A qualitative study of nurses. Applied Nursing Research, 40, 157-61. https://doi.org/10.1016/j.apnr.2018.02.002.

Malherbe, J. F. (1997). Pour une éthique de la médecine. Artel-Érasme.

Mucchieli, A. (2004). Dictionnaire des méthodes qualitatives en sciences humaines. Armand Colin.

Paillé, P., \& Mucchielli, A. (2012). L'analyse qualitative en sciences humaines et sociales. Armand Colin.

Papavasiliou, E., Brearley, S. G., Seymour, J. E., Brown, J., Payne, S. A.; EURO IMPACT. (2013). From sedation to continuous sedation until death: How has the conceptual basis of sedation in end-of-lifecare changed over time? Journal of Pain and Symptom Management, 46(5), 691-706. https://doi.org/10.1016/j.jpainsymman.2012.11.008.

Papavasiliou, E., Payne, S., Brearley, S., Brown, J., \& Seymour, J. (2013). Continuous sedation (CS) until death: Mapping the literature by bibliometric analysis. Journal of Pain and Symptom Management, 45(6), 1073-82.e10. https://doi.org/10.1016/j. jpainsymman.2012.05.012.

Perrot, S. (2016). Les bases neurophysiologiques de la douleur. Dans : Perrot, S. Douleur, soins palliatifs et accompagnement. Éditions MedLine, p. 17-30.

Pierron, J.Ph., Schumacher, B., \& Zielinski, A. (2019). Levinas et le soin. Numéro spécial (2019-1, nr. 14) de Ethique, politique, religions. Paris: Classiques Garnier.

Pudas-Tähkä, S. M., Axelin, A., Aantaa, R., Lund, V., \& Salanterä, S. (2009). Pain assessment tools for unconscious or sedated intensive care patients: a systematic review. Journal of Advanced Nursing, 65(5), 946-56. https://doi.org/10.1111/j.1365-2648.2008.04947.x.

Ribau, C., Lasry, J. C., Bouchard, L., Moutel, G., Hervé, C., \& MarcVergnes, J. P. (2005). La phénoménologie : une approche scientifique aux expériences vécues. Recherche en soins infirmiers, 81(2), 21-7. https://doi.org/10.3917/rsi.081.0021.

Ricœur, P. (1990). Soi-même comme un autre. Éditions du Seuil.

Royal Dutch Medical Association (KNMG). (2009). Guideline for Palliative Sedation Royal Dutch Medical Association. https:// palliativedrugs.com/download/091110_KNMG_Guideline_for_ Palliative_sedation_2009_2_\%5B1\%5D.pdf.

Sanders, R., Tononi, G., Laureys, S., Sleigh, J., \& Stat, D. (2012). Unresponsiveness $\neq$ Unconsciousness. Anesthesiology, 116(4), 94659. https://doi.org/10.1097/ALN.0b013e318249d0a7.
Saunders, C. (1993). Some challenges that face us. Second Congress of the European Association for Palliative Care Brussels, 19-22 October, 1992. Palliative Medicine, 7, 77-83.

Schildmann, E., \& Schildmann J. (2014). Palliative sedation therapy: A systematic literature review and critical appraisal of available guidance on indication and decision-making. Journal of Palliative Medicine, 17, 601-612.

Società Italiana di Cure Palliative. (2007). Raccomandazioni della SICP sulla sedazione terminale/ sedazione palliative. https://www. fondazioneluvi.org/wp-content/uploads/2017/01/SedazioneTerminale-Sedazione-Palliativa.pdf

Société québécoise des médecins de soins palliatifs and Collège des médecins du Québec. (2016). La sédation palliative en fin de vie. http://www.cmq.org/publications-pdf/p-1-2016-08-29-fr-sedationpalliative-fin-de-vie.pdf

Tomczyk, M., \& Dieudonné-Rahm, N. (2019). La conceptualisation de la sédation palliative par les infirmiers exerçant au sein de l'unité de soins palliatifs de l'Hôpital fribourgeois, en Suisse romande. Une recherche qualitative exploratoire. Recherche en soins infirmiers, 137, 6-17.

Tong, A., Sainsbury, P., \& Craig, J. (2007). Consolidated criteria for reporting qualitative research (COREQ): A 32-item checklist for interviews and focus groups. International Journal for Quality in Health Care, 19(6), 349-57. https://doi.org/10.1093/intqhc/mzm042.

Van Campenhoudt, L., \& Quivy R. (2011). Manuel de recherche en sciences sociales. Dunod.

Verspieren, P. (1984). Face à celui qui meurt. Desclée de Brouwer.

Ziegler, S., Schmid, M., Bopp, M., Bosshard, G., \& Puhan, M. A. (2018). Continuous deep sedation until death in patients admitted to palliative care specialists and internists: A focus group study on conceptual understanding and administration in Germanspeaking Switzerland. Swiss Medical Weekly, Aug 22; 148:w14657. https://doi.org/smw.2018.14657. eCollection 2018 Aug 13.

Zuleta-Benjumea, A., Muñoz, S. M., Vélez, M. C., \& Krikorian, A. (2018). Level of knowledge, emotional impact and perception about the role of nursing professionals concerning palliative sedation. Journal of Clinical Nursing, 27(21-22), 3968-78. https:// doi.org/10.1111/jocn.14582. 